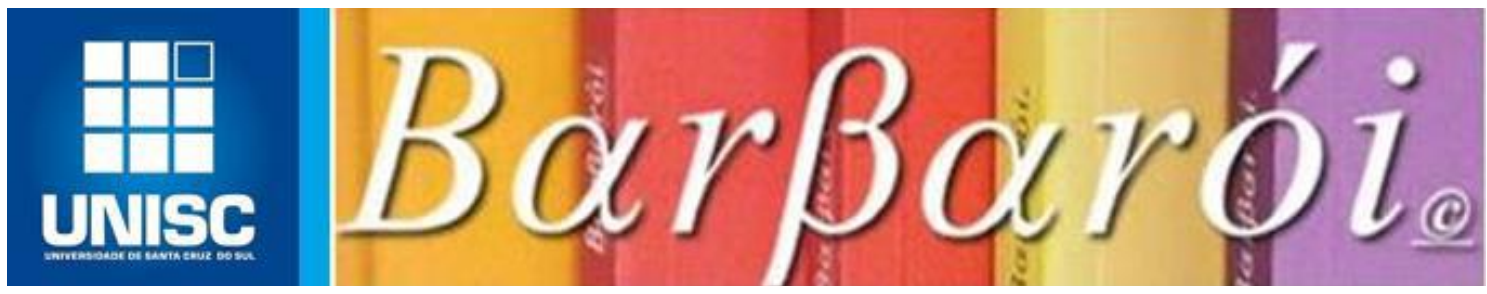

\title{
AVANÇOS E DESAFIOS DO TRABALO ASSOCIADO EM PROCESSO DE AUTOGESTÃO ${ }^{1}$
}

\author{
DOI: http://dx.doi.org/10.17058/barbaroi.v1i53.13072

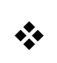

Tiago de Garcia Nunes

Universidade Católica de Pelotas - UCPel-Brasil

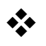

\begin{abstract}
Resumo
O objetivo deste artigo é verificar se, e, em que medida o processo autogestionário em quatro Organizações de Trabalho Associado (OTAs) pode impulsionar transformações cotidianas das relações de trabalho, e se este processo está relacionado a outras perspectivas mais amplas de resistência política. Tal abordagem, influenciada pela pesquisa-ação e pela enquete operária de Karl Marx, interpreta o impacto da relação (autogestão x processo de consciência) e os seus condicionantes, para problematizar os avanços e desafios da autogestão como mediação para aprimorar o processo de consciência e autodeterminação dos/as trabalhadores/as, ou seja: as rupturas e as continuidades do Trabalho Associado com a antiga forma (heterogestionária) merecem e precisam ser apuradas. $O$ cruzamento e a interpretação dos indicadores institucionais e comportamentais utilizados na pesquisa concluem a existência de 3 tipologias de consciência dominantes nas Organizações de Trabalho Associado em processo de autogestão.
\end{abstract}

Palavras-chave: Organizações de Trabalho Associado; Processo de Consciência; Autogestão.

\section{Introdução}

O objetivo do artigo é problematizar os avanços e desafios do trabalho associado (TA) a partir da comparação entre as distintas perspectivas autogestionárias identificadas em quatro OTAs (Organizações de Trabalho Associado) ${ }^{2}$ sob autogestão, tanto nas suas dimensões

\footnotetext{
${ }^{1}$ Artigo desenvolvido a partir da tese "A Autogestão em Perspectiva Comparada - Quatro Organizações de Trabalho Associado na Resistência da Produção à Contestação do Capital” (NUNES, 2016).

${ }^{2}$ Aqui e em todo o texto será empregada a terminologia Organização de Trabalho Associado (OTA) como gênero em que estão compreendidas algumas espécies de cooperativas populares, empreendimentos econômicos solidários, empresas recuperadas, fábricas ocupadas, coletivos informais e outras definições (VIEITEZ; DAL RI, 2010). O trabalho associado configura-se quando um coletivo detém posse ou a propriedade de uma unidade econômica passando a controlar a sua gestão, possuindo algumas características que o diferencia das empresas capitalistas, como: supressão do trabalho assalariado; retiradas (salários) iguais ou equitativas; substituições das hierarquias burocráticas por coordenações; deliberações em Assembleias gerais; nova perspectiva educacional para os trabalhadores, entre outras. Neste sentido, Dal Ri e Vieitez (2010) empregam a expressão OTAs maisBarbarói, Santa Cruz do Sul, n.53, p.<227-250>, jan./jun. 2019
} 
institucionais/organizativas como no que se relaciona à experimentação desta pelos trabalhadores. O marco teórico orienta-se pelo marxismo autogestionário, buscando subsídios teórico-metodológicos em autores filiados ao materialismo histórico e que se propuseram a pensar a imbricação entre a autogestão e o Trabalho Associado e, em certa medida, a relação dialética de ambas com os movimentos populares. Destacam-se as abordagens de Mészáros (2011), Nascimento (2004), Dal Ri e Vieitez (2001; 2010; 2011), Gaiger (2003) e Novaes (2011). Para tratar do tema da consciência foi utilizada a abordagem teórica de Mauro Iasi (IASI, 1999; 2007; 2012) sobre os processos de consciência e a metamorfose da consciência de classe, que o autor elabora a partir de algumas categorias de Jean-Paul Sartre (1979), Norbert Elias (1994) e Sigmund Freud (1978).

As experiências das OTAs são construídas por certas condições sociais que levam as marcas do momento histórico e da totalidade social concreta assentada sobre determinadas relações de poder que forjam um determinado tipo de comportamento e consciência nos trabalhadores. Assim, a presente abordagem não prioriza a compreensão do comportamento e da consciência como algo que o trabalhador deva alcançar como essência para constituir-se num sujeito transformador, ou seja: o que a consciência deveria ser para ser de classe, como uma fórmula cartesiana.

Assim, não se pode afirmar que a constituição de OTAs, é por si só, indício de um processo contra-hegemônico e que seus objetivos são antagônicos aos de uma sociedade estratificada em classes (TIRIBA, 2001). No entanto, dependendo dos elementos institucionais forjados dentro das OTAs, é possível compreender a experimentação autogestionária como um conjunto de mediações mais ou menos propícias para o desenvolvimento da consciência e da práxis que avance inclusive para outras esferas econômicas e políticas da realidade concreta.

Algumas OTAs podem apresentar elementos favoráveis ao surgimento de uma nova consciência (consciência revolucionária ou de classe), pois sustentam suas experiências em bases favoráveis a formação de outra forma de perceber o mundo e de interagir neste. Cooperação, disciplina, liberdade e autonomia se combinam e se repelem a cada instante. As rupturas e continuidades do Trabalho Associado com a antiga forma precisam ser constantemente avaliadas e desvendadas.

democráticas para designar empreendimentos com algumas características mais propensas ao engajamento em processos de mudança social. O trabalho associado está ainda inserido num sistema de cooperação com o capital. Assim, este surge quando essa mesma cooperação com o capital é empregada no intuito de forjar um sistema de cooperação autônomo ou para si. 


\section{Metodologia}

Foram selecionadas, intencionalmente, $4 \mathrm{OTAs}^{3} \mathrm{com}$ significativas diferenças, como: o ramo e a atividade fim; o envolvimento dos trabalhadores no seu surgimento; a organização territorial; a configuração institucional/formato jurídico; a forma de ingresso e associação de novos integrantes; a organicidade e a maior ou menor autonomia em relação a agentes externos. Tais diferenças refletem as distinções concretas entre os diversos tipos de OTAs na atualidade latino-americana. A autogestão no Trabalho Associado foi o elo analítico que permitiu equacionar experiências tão ricas e diversas. Assim, as conclusões apresentadas para os quatro casos estudados podem ser estendidas, com cuidado, a um universo mais amplo que o estudado. A pesquisa foi realizada a partir de um recorte histórico-sociológico com intuito comparativo que combinou a análise documental, audiovisual e eletrônica das organizações a outras fontes históricas escritas às técnicas de pesquisa de campo. Assim foi possível relacionar duas unidades dialeticamente relacionadas, a saber: (1) a organicidade do processo autogestionário em cada OTA e (2) o comportamento e a consciência individual e coletiva dos trabalhadores.

No que toca ao comportamento e a consciência foram realizadas 20 entrevistas semiestruturadas com questões diretivas e não diretivas aplicadas aos trabalhadores e trabalhadoras das OTAs e quatro entrevistas semiestruturadas aplicadas aos informanteschave das OTAs. Para levantar informações mais amplas sobre a realidade organizacional das OTAs foram utilizados ainda os seguintes procedimentos metodológicos: pesquisa-ação e militante com participação em diversas situações deliberativas, formativas e recreativas das OTAs durante o período compreendido entre 2012-2016; pesquisa bibliográfica das e sobre ${ }^{4}$ as OTAs; pesquisa documental nos arquivos internos das OTAs; pesquisa fotográfica e audiovisual; pesquisa eletrônica em Blogs e páginas nas redes sociais das organizações, assim como nos murais, vídeos, materiais informativos, panfletos, programas de rádio etc. Importante destacar a influência exercida pela estrutura e pelos pressupostos epistemológicos e políticos da Enquete Operária (MARX, 1984) sobre nossos roteiros de entrevista e indicadores. O questionário de 1880 inaugura uma importante discussão sobre a prática do

\footnotetext{
${ }^{3}$ Foram investigadas 4 OTAs brasileiras: Fábrica Ocupada Flaskô (SP), CooperActiva Okupa 171 (RS), Cooperativa Teia Ecológica (RS), Núcleo de Produção Elementos da Terra (RS).

${ }^{4}$ Importante destacar que os movimentos populares têm avançado no protagonismo da produção do conhecimento, muitos deles, com editoras e bibliotecas próprias para este fim.
} 
movimento socialista e do papel das enquetes como modo de investigação ação e de trabalho político junto ao movimento operário e à classe trabalhadora. ${ }^{5}$

Neste intuito foram desenvolvidos e aplicados os seguintes instrumentos de pesquisa: a) um roteiro semi-estruturado para entrevista dos informantes-chave e coleta de dados referentes às OTAs contendo 23 tópicos divididos em três grandes eixos; b) um roteiro estruturado para entrevista dos trabalhadores das OTAs contendo 83 questões diretivas e não diretivas.

\section{A autogestão como referencial teórico-analítico para compreender o Trabalho Associado na vigência do Capital}

Uma grande dificuldade recai nos ombros de qualquer pesquisador ou militante que se desafie a definir, compreender ou aplicar a autogestão como categoria analítica. As análises existentes oscilam entre o registro historiográfico das várias experiências que incorporaram em maior ou menor intensidade a auto-organização plena da vida; a exposição dos fundamentos epistemológicos das matrizes teóricas dos principais autores que trataram da temática; ou ainda, os elementos centrais da própria práxis autogestionária.

Marx falou em modo de produção de produtores associados (1998; 1982) e se declarou favorável às cooperativas de produção ${ }^{6}$. No entanto, não se debruçou sobre a discussão da organização autogestionária ou do socialismo em bases autogestionárias de forma direta. Talvez não tenha dado tempo de enfrentar tal empreitada. Assim, a autogestão pode ser apresentada como teste de ferro a qualquer processo, evento ou experiência que se autoproclame socialista, pós-capitalista ou emancipatório.

\footnotetext{
${ }^{5}$ A enquete operária trata-se de um questionário elaborado em 1880 por Karl Marx, composto por 100 perguntas dirigidas aos operários franceses do campo e da cidade, pois "apenas eles podem descrever, com todo o conhecimento de causa, os males que suportam, e de que só eles, e não os salvadores providenciais, podem energicamente remediar as misérias sociais que sofrem" (1984, p. 249). Com a ironia que lhe era peculiar, Marx definiu que objetivo da enquete era o de animar o governo republicano francês a seguir o exemplo do governo monárquico inglês.

${ }^{6}$ Em várias passagens Marx e Engels utilizaram os termos trabalho associado, produção coletiva, sociedades cooperativas e associação cooperativa para definir uma célula no interior do modo de produção fundada na negação do trabalho assalariado, na propriedade e gestão coletiva dos meios de produção e na distribuição igualitária dos frutos do trabalho dentro do contexto da sociedade capitalista. Nas Instruções para os Delegados do Conselho Geral Provisório, Marx (1982) reconhece a importância do movimento cooperativo como uma das forças transformadoras da sociedade baseada em antagonismo de classes, destacando o seu grande mérito em "mostrar praticamente que o presente sistema, pauperizador e despótico, de subordinação do trabalho ao capital pode ser superado pelo sistema republicano e beneficente de associação de produtores livres e iguais" (np). Mas adiante alerta que "restringido, contudo, às formas anãs, em que escravos assalariados individuais o podem elaborar pelos seus esforços privados, o sistema cooperativo nunca transformará a sociedade capitalista" (np). O autor sugere que para que a produção cooperativa ataque o alicerce do sistema econômico, é preciso que converta a produção social num sistema amplo e harmonioso de trabalho livre e cooperativo com "mudanças sociais gerais, mudanças das condições gerais da sociedade, que nunca serão realizadas a não ser pela transferência das forças organizadas da sociedade (...) para os próprios produtores" (np).
} 
Para muitos autores a autogestão aparece como sinônimo de forma ideal de organização dos trabalhadores em situação pós-revolucionária, pós-capitalista ou ainda pósEstado, com ou sem a tomada do poder político. Para outro grupo de teóricos, a autogestão é concebida como forma social possível dentro do próprio capitalismo, entendendo que os trabalhadores podem conquistar autonomia política e econômica, sem a necessidade de conquista do poder político e econômico e que este é o caminho para a sociedade dos produtores livremente associados.

O principal paradoxo da autogestão foi assinalado por Daniel Mothé, na obra Autogestão gota a gota (MOTHÉ, 1980 apud NASCIMENTO, 2013). O autor problematizou os principais nós do socialismo autogestionário a partir de algumas reflexões, são elas: (a) como articular a autogestão como ideologia com as experiências práticas? (b) Só pode existir autogestão com a Revolução (dilúvio), ou, esta também pode existir com experiências pontuais (gota a gota)? (c) Seria possível conciliar a audácia do projeto autogestionário com a limitação das tentativas de gestão das unidades produtivas?

Buscando dar respostas a estas indagações, Mothé formulou a ideia da autogestão gota a gota, dentro de uma visão ampla de experimentação, baseada também na perspectiva de Rosa Luxemburgo. Sob tal paradoxo, Mothé defendeu a participação dos trabalhadores em experiências de funcionamento coletivo nas empresas de autogestão, mesmo que limitadas quando inseridas na lógica do capital.

Contudo, a autogestão ganha materialidade histórica a partir do resgate de diversas experiências, eventos ou processos pretéritos e atuais; dotados de distintos sentidos, formas, contextos e condições subjetivas/objetivas (pois nem sempre se constituem em períodos revolucionários nos quais está em jogo a conquista do Estado ou a ruptura com o sistema capitalista); apresentando diferentes graus de controle dos meios de produção e sustentabilidade no tempo. A história conheceu vários experimentos autogestionários, não cabe aqui cita-los.

Cláudio Nascimento aponta uma saída ao dilema, quando, despretensiosamente, registra que a "autogestão é uma estratégia-movimento social e um ideal-teoria social" (2013). O autor assinala que a autogestão, antes de tudo, é referenciada em eventos e processos históricos mais ou menos duradouros e capilarizados, nos quais os trabalhadores tentaram o assalto ao céu.

É notório que nos últimos tempos, a autogestão passou a ser banalizada e utilizada livremente como palavra de ordem e tema de pesquisas, criando uma espécie de saco de 
gatos $^{7}$. Sob esse horizonte, torna-se importante validar a essência histórica da categoria autogestão como estratégia-movimento e ideal-teoria social, a fim de utilizá-la para avaliar as possibilidades emancipatórias do Trabalho Associado (TA) na vigência do capital, problematizando suas rupturas e continuidades.

No que diz respeito às análises contemporâneas sobre o $T A$, percebe-se uma polarização entre as interpretações que enaltecem, por um lado, que tudo mиdou como num passe de mágicas e as leituras que denunciam, por outro, que nada mudou, como se estes coletivos nem tivessem existido. Em que pesem algumas importantes exceções, tal maniqueísmo ainda pauta boa parte da discussão acadêmica e política sobre as experiências e processos de trabalho associativo.

Henrique Novaes (2011), ao analisar a alienação e as possibilidades de desalienação em associações de trabalhadores, sinaliza a existência de inúmeros problemas na análise destas experiências pelos pesquisadores latino-americanos e aponta três tendências dominantes nas pesquisas realizadas até o momento: (1) tudo mudou; (2) nada mudou e (3) visão microscópica da realidade social. De um lado, alguns pesquisadores afirmam que tudo mиdои depois do arrendamento ou aquisição dos meios de produção pelos trabalhadores de fábricas recuperadas e cooperativas de trabalhadores. No outro extremo, existe uma linha argumentativa do nada mudou, pois as associações e cooperativas estão diante do sistema produtor de mercadorias e a relação capital-trabalho se reproduz dentro de todas as empresas, sejam elas de trabalhadores ou de patrões. Em relação à terceira tendência, embora composta por perspectivas que não caem na falácia do enquanto não tomarmos o poder, nada mudará, e de mostrar as permanências e mudanças nas fábricas recuperadas e cooperativas de trabalhadores, tende a adotar uma visão microscópica da realidade social (2011). Neste sentido, Novaes aponta a existência de uma ainda incipiente quarta via argumentativa. Esta via - que apresenta consequências não só analíticas, mas para a ação política - é esboçada a partir das trilhas deixadas por Marx, quando estabelece a dialética da parte com o todo: das rupturas com a antiga forma e a reprodução da antiga forma, para sinalizar as possibilidades de ruptura social do movimento associativo reconhecendo-o como uma das forças transformadoras da sociedade atual baseada em antagonismo de classes, mas sem, contudo deixar de apontar a suas limitações para derrubar o sistema social do capital.

\footnotetext{
${ }^{7}$ Para elucidar o problema, Guillerm e Bourdet (1976) mencionam o episódio de uma publicação feita na época que aplicou o termo autogestão para caracterizar o direito dos detidos numa cela presidiária de se encarregarem, diariamente e por rodízio, da missão de despejar o urinol.
}

Barbarói, Santa Cruz do Sul, n.53, p.<227-250>,jan./jun. 2019 
Assim, os horizontes de percepção construídos por Dal Ri e Vieitez (2001; 2010; 2011), Gaiger (2003) e Novaes (2011), são interessantes exemplos de superação das limitações analíticas e políticas das três tendências investigativas sobre o TA, abrindo caminho para uma quarta via. Para Vieitez e Dal Ri há mudanças nas fábricas recuperadas, principalmente na organização e nas relações de trabalho, bem como na gestão. Contudo, os autores afirmam que as modificações realizadas até agora não dão conta de transformar a essência das fábricas - produção de mercadorias, supremacia dos quadros etc.; assim a possibilidade de avanço estaria na articulação das fábricas recuperadas, cooperativas e associações de trabalhadores com o movimento de luta mais geral dos trabalhadores, e de uma visão e um programa de modificação da sociedade, e não apenas de unidades produtivas.

Para Gaiger, as formas produtivas do universo da Economia Solidária são atípicas, porém podem conviver - sem abalar - o capitalismo; para que estas se convertam num novo modo de produção que transcenda a alienação do trabalho, são necessárias mudanças significativas. Entende-se que a leitura desses quatro autores permite superar as limitações analíticas das três tendências apontadas, conectando o campo analítico ao elemento político do TA na medida que as OTAs - quando concebidas como sujeitos políticos -, prefiguram ou nos mostram alguns dos elementos do que seria uma forma superior de produção, baseada no trabalho coletivo: com sentido social e com possibilidades de emancipação humana e política. Evidentemente que as OTAs não se realizam em sua plenitude porque estão imersas no modo de produção capitalista; apresentam descontinuidades na continuidade e continuidades na descontinuidade, conforme apontado por Mészáros na caracterização dos avanços e retrocessos do cooperativismo e associativismo no século XXI (2011).

Ao se conferir desproporcional atenção ao tema das decisões democráticas realizadas dentro dos muros de cooperativas populares, associações de trabalhadores e fábricas recuperadas em detrimento de uma crítica profunda dos mecanismos de mercado, acaba-se por negligenciar o tema da alienação e da desalienação dos trabalhadores e a sua potencialidade enquanto horizonte de transformação social. A plasticidade do termo autogestão comporta designações analíticas que vão desde aquelas que incitam o controle das empresas pelos trabalhadores competindo no mercado; as que defendem o socialismo de mercado; até as que postulam a necessidade de se combinar ataques duplos ${ }^{8}$, ou seja:

\footnotetext{
${ }^{8}$ A ideia dos ataques duplos foi extraída de uma passagem da obra de Mészáros quando imbuído da tarefa de uma teoria da transição, propõe-se a responder o complexo questionamento: "como solapar o processo produtivo capitalista constantemente renovado pela homogeneização orientada para a quantidade e o valor de troca e substituí-lo pelo processo qualitativo orientado para a necessidade e o valor de uso?" (MÉSZÁROS, 2011, p. 629-630).
}

Barbarói, Santa Cruz do Sul, n.53, p.<227-25o>,jan./jun. 2019 
mudanças na divisão do trabalho nas fábricas e associações até o planejamento global da produção e distribuição. Não surpreende que a retomada do $T A$ enquanto prática popular tenha revigorado o debate histórico acerca dos seus limites e potencialidades, tanto no campo acadêmico como na esfera política. Nestes termos, os clássicos debates entre o socialismo utópico e científico e sobre a natureza degenerativa das cooperativas vêm incorporando novos elementos, como o aspecto da consciência dos trabalhadores das OTAs e a crítica da alienação como possibilidade de questionamento das (des)continuidades da perda do controle do produto do trabalho numa sociedade regida pelo capital, mesmo em associações de trabalhadores, onde aparentemente a questão da transferência da propriedade dos meios de produção já se encontra realizada.

Neste sentido, importa questionar: Por que os embriões de uma nova consciência aparecem somente em algumas OTAs? Se os elementos organizativos são as variáveis determinantes dessa possibilidade, de onde eles vêm, considerando que a organicidade dos grupos é constituinte, mas também constituída pelos próprios trabalhadores? Como se da o processo de consciência dos trabalhadores das OTAs?

\section{Desvendando o comportamento e a consciência em Organizações de Trabalho Associado}

\section{- avanços e desafios. Indicadores institucionais organizativos e comportamentais} (consciência)

A subjetividade é um assunto muito relevante ao debate marxista. Durante um largo período a leitura positivista das obras de Marx negligenciou a relevância do tema da subjetividade, tratando-a como desimportante na análise dos fenômenos sociais. No debate sobre a consciência de classe não havia muito a se dizer - cada classe com sua consciência própria, se esta não estava a manifestando propriamente, bastava despertá-la. O debate sobre a consciência se estende em diversas direções e se orienta por distintas matrizes epistemológicas: Anthony Giddens, Jürgen Habermas, Pierre Bourdieu, Émile Durkheim, Claude Lévi-Strauss, além de Marx, trabalharam, conservadas as suas peculiaridades, questão relacionadas ao exterior/interior, objetivo/subjetivo. Alguns deles empregam ainda outras noções como reflexividade, discursividade, racionalidade, habitus; mas todas comungam da noção de subjetividade.

Para tratar dos dados empíricos utilizou-se a abordagem teórica de Mauro Iasi (IASI, 1999; 2007; 2012) sobre os processos de consciência e a metamorfose da consciência de classe, que o autor elabora a partir de algumas categorias de Jean-Paul Sartre (1979), Norbert Elias (1994) e Sigmund Freud (1978). 
Em síntese, Iasi considera a consciência como processo e identifica três momentos, que conforme o autor, não podem ser considerados meras etapas lineares, mas sim uma tipologia para auxiliar na compreensão da forma como os sujeitos compreendem e interferem no mundo, a saber: (1) primeira forma de consciência - a alienação subjetiva, manifesta pela ultrageneralização da realidade e pela submissão do indivíduo às relações e aos valores sociais $\operatorname{dados}^{9}$; (2) segunda forma de consciência - consciência em si, marcada pela incidência de contradições da primeira forma de consciência e pelo surgimento do sentimento de grupo, da consciência do grupo $^{10}$; (3) terceira forma de consciência - consciência para si, nova consciência, consciência humana ou de classe ${ }^{11}$. A partir desta tipologia, os indicadores institucionais e comportamentais da pesquisa foram construídos no intuito de denunciar e interrogar os aspectos objetivos e subjetivos da relação de exploração, alienação e opressão da classe trabalhadora dentro do sistema do Capital.

Uma prática comum na literatura sobre o associativismo/cooperativismo é a de tomar, sem maiores reflexões, a solidariedade e a autogestão como elementos já alicerçados e capilarizados entre os trabalhadores dos coletivos, negligenciando que também existem alienações nas propostas que almejam justamente a emancipação dos trabalhadores. Em sentido similar, os comportamentos são tomados como solidários e participativos sem identificar as intencionalidades dos trabalhadores e as suas oscilações. Sem compreender os elementos subjetivos e objetivos da alienação fica impossível avaliar as possibilidades de

\footnotetext{
${ }^{9}$ Iasi sintetiza a primeira forma de consciência em sete elementos (1) A vivência de relações que já estavam preestabelecidas como realidade dada; (2) a percepção da parte pelo todo, onde o que é vivido particularmente como uma realidade pontual, torna-se a realidade (ultrageneralização); (3) por esse caminho, as relações vividas perdem seu caráter histórico e cultural para se tornarem naturais, levando à percepção de que sempre foi assim e sempre será; (4) a satisfação das necessidades, seja da sobrevivência ou do desejo, deve respeitar a forma e a ocasião que não são definidos por quem sente, mas pelo outro que tem o poder de determinar o quando e o como; (5) essas relações não permanecem externas, mas se interiorizam como normas, valores e padrões de comportamento, formando com o superego, um componente que o indivíduo vê como dele, como autocobrança e não como uma exigência externa; (6) na luta entre a satisfação do desejo e a sobrevivência, o indivíduo tende a garantir a sobrevivência, reprimindo ou deslocando o desejo; (7) assim, o indivíduo submete-se às relações dadas e interioriza os valores como seus, zelando por sua aplicação, desenvolvimento e reprodução (IASI , 2007, p.1819).

${ }^{10}$ A consciência em si representa ainda a consciência que se baseia na vivência das relações e dos interesses imediatos, não mais do ponto de vista do indivíduo, agora do grupo, da categoria, e pode evoluir até a consciência de classe. Para Iasi, ela é parte fundamental da superação da primeira forma de consciência, portanto, da alienação; no entanto, seu pleno desenvolvimento ainda evidencia traços da antiga forma ainda não superados (IASI, 2007). Interessante a definição de Lia Tiriba quando descreve esta etapa da consciência como sendo a passagem do egoísmo individual ao egoísmo coletivo. "Se por um lado, o egoísmo coletivo parece ser m avanço em relação ao egoísmo individual, de outro, o egoísmo não deixa de ser egoísmo" (TIRIBA, 2001, p. 351).

${ }^{11}$ Neste nível de consciência, o sujeito percebe que sua emancipação só ocorrerá pela superação da sociedade dividida em classes sociais, ou seja, com a emancipação profunda de toda a sociedade. Para Iasi, a superação da segunda forma de consciência pode ocorrer a partir do que Sartre chamou de Processo dialético de totalização mediado pelos grupos, capaz de provocar o descontentamento dos sujeitos e convertê-lo em livre práxis (SARTRE, 1979).
}

Barbarói, Santa Cruz do Sul, n.53, p.<227-250>,jan./jun. 2019 
(des)alienação dos trabalhadores pela sua inserção em experiências de trabalho associado ou ainda tencionar em que medida a autogestão pode ou não ser (mais) um instrumento de mediação e de auto-organização da classe trabalhadora assumida pelas massas enquanto fato de poder. Frente à diminuta disponibilidade de indicadores desta natureza na literatura, o resultado preliminar da pesquisa redundou na elaboração de indicadores institucionais e comportamentais, muitos deles apontados pelos próprios trabalhadores durante as entrevistas e atividades internas das OTAs.

\section{Indicadores institucionais/organizativos de autogestão}

Os indicadores institucionais que circundam a realidade das Organizações de Trabalho Associado pesquisadas foram divididos em três grandes blocos estruturantes: (1) identidade da OTA; (2) autogestão interna: organicidade, cooperação, autonomia e participação; (3) autogestão societal ampliada: elementos de socialização autogestionária e tendências para a integração socioprodutiva ampliada.

No primeiro bloco - identidade da OTA - procurou-se levantar elementos relacionados aos aspectos constitutivos das organizações. Neste bloco foram analisados 6 indicadores: (1) envolvimento dos trabalhadores no surgimento da OTA; (2) o isolamento ou integração da estrutura produtiva; (3) configuração institucional/formato jurídico definido propriedade e/ou da posse segura dos meios de produção e a existência ou não de debate sobre o regime jurídico; (4) forma de ingresso e associação e critérios técnicos e políticos definidos assim como incidência de terceirização na unidade produtiva; (5) participação e relação institucional da OTA com movimentos populares, solidariedade de classe e organicidade e autonomia em relação a parceiros, apoiadores e agentes externos; (6) existência de um programa político, das demandas imediatas ou visão de sociedade. Note-se que apesar de os indicadores " 1 ", "2" e “3" estarem organizados no bloco identidade, estes possuem total relação com o terceiro bloco: autogestão societal ampliada. Foram aqui alocados por parecerem atributos centrais para definir a identidade da OTA. Utilizou-se a Identidade numa acepção sociológica simplificada no sentido de apontar características e diferenciar uma OTA de outra.

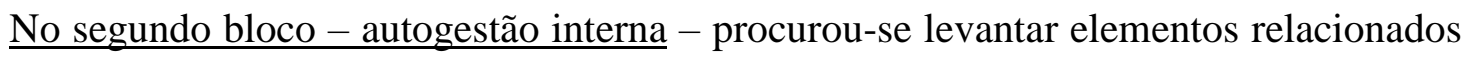
aos mecanismos de gestão das OTAs. Foram pesquisadas: a estrutura de produção e sua integração com canais internos de participação direta e representação - existências de diferentes setores, seções, coordenações, conselhos, frequência de assembleias, formas de eleição dos representantes, tempo de mandato, periodicidade das reuniões e percentual de Barbarói, Santa Cruz do Sul, n.53, p.<227-250>,jan./jun. 2019 
participação, encontros preparatórios, estruturas vinculadas a agentes externos e a parceiros; a divisão do trabalho dentro das organizações - retirada, papéis e funções, cotas de participação, vínculo dos trabalhadores com a OTA, hierarquias, jornada de trabalho, índice de absenteísmo, acidentes de trabalho, conflitos internos; instrumentos e canais de informação e formação continuada voltadas para o processo produtivo e para a autogestão interna. Foram desenvolvidos 11 indicadores: (7) tipologia da gestão - heterogestão, co-gestão, administração participativa ou autogestão; (8) canais de participação e deliberação; (9) canais de troca de informações; (10) representação, rotatividade de cargos e revogação de mandato; (11) divisão e forma de definição de funções e papéis; (12) existência de diferença de retirada ou remuneração entre os trabalhadores e o grau de maturidade e discussão sobre o tema; (13) nível de colaboração e cooperação entre diferentes setores; (14) carga horária e intensidade da jornada de trabalho em comparação com o trabalho heterogestionário formal; (15) canais internos de informação e comunicação; (16) intensidade da participação (em sentido qualitativo e quantitativo) dos trabalhadores; (17) oferta de atividades internas de formação técnica e/ou gestão associada.

No terceiro bloco - autogestão societal ampliada - o objetivo foi capturar elementos de socialização autogestionária para avaliar maiores e menores tendências para a integração socioprodutiva ampliada e a capacidade de mobilização política das OTAs. Nesta etapa, talvez a mais relevante da pesquisa, foi desenvolvido um instrumental metodológico para verificar em que medida as organizações estudadas estão comprometidas com a socialização dos avanços obtidos no interior da unidade produtiva a partir da incorporação de estratégias ampliadas de luta política, de superação do trabalho alienado e de controle sociometabólico da produção, da circulação e do consumo, potencializando um associativismo combativo e comprometido com interesses da classe trabalhadora. Neste bloco o trabalho de campo procurou captar: (a) as estruturas/canais de informação e formação continuada, divulgação externa, mobilização política e $\operatorname{AGITPROP}^{12}$ (agitação e propaganda) e (b) relação e integração orgânica práticas de outros atores sociais e econômicos. Foram definidos 15 indicadores: (18) existência da expressão autogestão ou expressão análoga nos canais de comunicação; (19) registro de memória política e histórica da OTA; (20) solidariedade a

${ }^{12} \mathrm{O}$ termo AGITPROP foi disseminado por diversos países, bem como as experiências dos grupos, brigadas ou coletivos de agitadores e propagandistas. A expressão agitação e propaganda foi criada pelos revolucionários russos, para designar as diversas formas de fazer agitação de massas e ao mesmo tempo divulgar os projetos políticos da revolução (GARCIA,1990). O coletivo de comunicação, cultura e juventude da Via Campesina define a agitprop como: "um conjunto de métodos e formas que podem ser utilizados como tática de agitação, denúncia e fomento à indignação das classes populares e politização de massas em processos de transformação social” (COLETIVO DE COMUNICAÇÃO, CULTURA E JUVENTUDE DA VIA CAMPESINA, 2007) 
outras experiências de trabalho associado e a movimentos populares; (21) atividades de formação/mobilização política e existência de setor específico para tal finalidade; (22) existência de espaço próprio ou adaptado para leitura e aprendizagem dos trabalhadores, familiares e vizinhos assim como de produção de conhecimento próprio (panfleto, jornal, mural, livro, zines, quadrinhos); (23) práticas artístico-culturais como artes plásticas (grafitagem, muralismo, painelismo, faixas, cartazes, fotografia, estêncil), teatro (teatro jornal, teatro fórum, teatro invisível, teatro procissão, teatro de rua, apresentações livres de rua, mostras) ou música e poesia (corais, saraus, festivais, apresentações em rádio e televisão); (24) produção e utilização de indumentária e vestimenta pelos trabalhadores e pela comunidade (bonés, camisetas, bandeiras, broches); (25) meios de comunicação de massa (programa de rádio, televisão e/ou internet, cinema, jornal, blog e páginas nas redes sociais); (26) relações políticas orgânicas da OTA com outras OTAs, movimentos sociais, entidades de apoio, redes, outros coletivos e/ou com o Estado; (27) relações econômicas da OTA com outras OTAs, movimentos sociais, redes, entidades de apoio e/ou Estado; (28) existência de registro detalhado do programa político ou das demandas do movimento social referência transversalidade de pautas da OTA com outras pautas ou lutas sociais do movimento referência ou de outros movimentos; (29) canais de escoamento da produção por fora do mercado capitalista- incorporação da produção com a circulação, o crédito e o consumo assim como a integração da produção com sistemas de compra direta governamental, com feiras agroecológicas/solidárias, cooperativas de consumo, Grupos de Consumo Responsável, sistemas CSA (Comunidade que Sustenta a Agricultura), Sistema Orgânico do Trabalho etc.; (30) avaliação e planejamento para o desenvolvimento da OTA - aspectos financeiros, de gestão, participação, cooperação interna e externa, autogestão ampliada, acesso à crédito e intercooperação econômica e política com outros empreendimentos; (31) compartilhamento de espaços, recursos produtivos, economias de rede, serviços, crédito solidário/intercooperativo, bens e objetos com outras OTAs ou redes de OTAs; (32) atividades de integração sociopolítica com as famílias dos trabalhadores e a comunidade na qual a OTA está inserida, além de relacionamento com outras instituições como associação de moradores, coletivos artístico-culturais, cursos EJA (educação para jovens e adultos), escolas, universidades etc.

Para cada indicador institucional/organizacional foram fixados quatro níveis para quantificar maiores e menores tendências institucionais com mediações propícias para o desenvolvimento da consciência e prática autogestionária, distribuídas nos seguintes níveis: 
nível (1) socialmente inaceitável; nível (2) aceitável; nível (3) socialmente necessário; nível (4) padrão idealizado (veja-se abaixo nas imagens 1 e 2).

\section{Indicadores comportamentais - consciência dos trabalhadores}

Os indicadores comportamentais foram elaborados com o intuito de captar aspectos relativos à consciência individual de cada trabalhador a partir da sua reflexão e práxis autogestionária para posteriormente aferir em que medida os diferentes indicadores institucionais/organizacionais influenciam (e se influenciam) o comportamento, a cultura e a prática autogestionária dos trabalhadores, ou seja: realizar o cruzamento entre os indicadores institucionais e comportamentais.

Se existem diferentes maneiras de cooperar, participar e protagonizar torna-se imprescindível entender com qual intencionalidade os trabalhadores experimentam os eventuais avanços obtidos no interior das unidades produtivas. Os indicadores comportamentais foram divididos em 3 (três) grandes blocos estruturantes: (1) consciência e comportamento dos trabalhadores em relação à autogestão interna: organicidade, cooperação, autonomia, participação, disciplina, confiança e liberdade; (2) consciência e comportamento dos trabalhadores em relação à autogestão societal ampliada: solidariedade de classe, participação e mobilização política, relação com movimentos e outros atores sociais; (3) posicionamento sobre aspectos sociopolíticos gerais, entendidos como politicamente relevantes no momento histórico de realização do trabalho de campo. ${ }^{13}$

No primeiro bloco - autogestão interna - o trabalho de campo procurou, a partir de 14 indicadores, captar dos trabalhadores: (1) compreensão sobre a autogestão ou expressões análogas como autonomia, auto-organização, controle dos trabalhadores etc; (2) percepção sobre a divergência de opiniões e conflitos de ideias; (3) percepção sobre a cooperação entre os trabalhadores; (4) participação nas decisões; (5) conhecimento dos canais de participação; (6) apropriação das informações; (7) protagonismo; (8) participação nas atividades internas e externas de formação técnica; (9) motivação para trabalhar numa OTA; (10) percepção sobre a divisão do trabalho e tarefas; (11) existência de avaliação própria sobre a situação da OTA;

\footnotetext{
${ }^{13}$ No âmbito da pesquisa cada entrevista foi aplicada em blocos, não obedecendo à mesma ordem definida pelos roteiros, pois uma mesma sequência não é capaz de provocar as mesmas reações em diferentes sujeitos. Durante as entrevistas surgiram muitas dúvidas e profícuos debates sobre os temas, em especial em relação ao bloco aspectos sociopolíticos gerais do roteiro individual. Quando solicitado a prestar esclarecimento sobre temas desconhecidos aos entrevistados, procurou-se dialogar de forma simples e clara sobre os contornos da temática, buscando sempre evitar a usual e arrogante reação moral do entrevistador decorrente da desinformação do entrevistado.
} 
(12) o ponto de vista sobre a carga horária e a intensidade do trabalho; (13) discernimento sobre a remuneração do trabalho; (14) a avaliação sobre o que é preciso aprimorar na OTA.

No segundo bloco - autogestão societal ampliada - o objetivo foi avaliar a participação dos trabalhadores em atividades políticas internas e externas que extravasem os muros da unidade produtiva assim como a sua percepção sobre as relações políticas e econômicas estabelecidas pela OTA com outras OTAs e atores sociais. Com isso, intentou-se decifrar em que medida a solidariedade com a classe trabalhadora está presente no imaginário dos trabalhadores e qual a sua percepção sobre uma eventual confluência dos objetivos corporativos da OTA com bandeiras de lutas mais amplas e a socialização dos eventuais avanços obtidos no interior da sua organização. Foram definidos 8 indicadores para o segundo bloco: (15) compreensão da importância da OTA para além da produção; (16) consciência sobre o histórico da OTA - memória pessoal sobre o momento de sua criação, principais mobilizações políticas, períodos de crise e vitórias ocorridas; (17) interesse por atividades internas e externas de formação política e a efetiva participação nestas; (18) realização de vivências em outras experiências de trabalho associado; (19) compreensão sobre a existência de relações com outros atores e como estas são feitas - capacidade de identificar aliados, parceiros e adversários da OTA; (20) consciência a respeito da existência de relações econômicas em nível micro e macro econômico e a influência destas no funcionamento da OTA; (21) reflexão sobre perspectivas ampliadas de autogestão tanto na esfera política como econômica - compartilhamento de espaços, recursos produtivos, economias de rede, serviços, crédito solidário, bens e objetos com outras OTAs, organizações e movimentos populares, entidades de apoio ou redes de OTAs e o Estado; preocupação com a integração sociopolítica da OTA com as famílias dos trabalhadores e a comunidade na qual a OTA está inserida e com organizações e movimentos populares, associação de moradores, partidos políticos, sindicatos, coletivos artístico-culturais, cursos EJA, escolas/universidades etc; opinião em relação a existência de relações políticas locais, regionais, nacionais e internacionais assim como a importância de contribuir nas lutas de trabalhadores e movimentos sociais.

No terceiro bloco - aspectos sociopolíticos gerais - o propósito foi o de avaliar a consciência dos trabalhadores a partir da sua compreensão e posicionamento em relação a temas relevantes à classe trabalhadora e com grande repercussão nos meios de comunicação. Num primeiro momento os trabalhadores foram questionados se sabiam o que significava cada um dos temas e em caso de resposta afirmativa, foram estimulados a manifestar a sua 
opinião. ${ }^{14}$ Foram desenvolvidos indicadores sobre os seguintes temas: (22) opinião sobre os movimentos sociais populares e a participação nestes ou em alguma organização social, partido político, entidade assistencial e capacidade de relacionar a atividade da OTA com as suas pautas e bandeiras de luta; (23) histórico e percurso militante do trabalhador assim como a apropriação em relação ao movimento social ao qual a OTA faz parte e participação neste; (24) posição em relação à reforma agrária; (25) redução da maioridade penal para fins de condenação; (26) cotas raciais e sociais de acesso ao ensino superior e outras instituições públicas; (27) união homoafetiva ou casamento gay; (28) capacidade das mulheres para exerceram cargo de direção, coordenação ou chefia - igualdade de gênero; (29) reflexão sobre o modo de produção capitalista como modo de organização social; (30) sobre a existência de preconceito de raça, gênero, classe no Brasil; (31) legitimidade dos partidos políticos e compreensão sobre a participação política direta e indireta; (32) grau de confiança nos meios de comunicação hegemônicos de massa.

\section{Resultados e Conclusões}

Na sociedade sob domínio do Capital, enquanto seu sociometabolismo alcança todas as esferas da vida, não é possível alcançar uma nova consciência, a não ser de forma embrionária. Os trabalhadores são indivíduos inseridos nesta sociedade e talvez dispostos a transformá-la. No entanto, outra consciência não se desenvolve sem uma nova ordem de relações sociais. Não se pretende com isso afirmar que a transformação material da atual sociedade só ocorrerá quando as novas consciências estiverem aptas a fazer a transformação material, e que após isso, ela ocorrerá automaticamente. Ainda que preservada certas determinações materiais, as esferas objetivas e subjetivas combinam-se, assim que a luta de ideias e a capacidade de uma classe demonstrar suas concepções e valores de forma estratégica, preparam o terreno para transformações, até revolucionárias.

Compreender a consciência como um processo permite reconhecer que esta não é estática ou que se desenvolve de forma linear; é formada a partir da relação dialética existente entre as representações ideais dos indivíduos e as suas relações concretas.

Os resultados da pesquisa sugerem importantes pistas sobre o desenvolvimento dos processos de consciência no interior das OTAs. Assim, conclui-se que as experimentações autogestionárias podem, sob algumas condições, engendrar mediações propícias para o desenvolvimento de práticas democratizantes no processo de trabalho, com a eventual

\footnotetext{
${ }^{14}$ As respostas não foram tabuladas a partir da predefinição de uma resposta correta ou mais correta sobre cada assunto, mas a partir da reação demonstrativa de entendimento e capacidade reflexiva sobre cada tema.
}

Barbarói, Santa Cruz do Sul, n.53, p.<227-250>,jan./jun. 2019 
socialização dos avanços obtidos no interior das unidades produtivas. No entanto, as rupturas com a forma heterogestionária não eliminam as continuidades com a sua lógica do trabalho: o horizonte da emancipação dos trabalhadores não está totalmente assegurado. Por outro lado, as continuidades não aniquilam as rupturas. Para tanto, as condições e mediações relacionadas aos avanços e aos desafios; às rupturas e continuidades, precisam ser criticamente apuradas. A tipologia de Mauro Iasi $(1999 ; 2007)$ aplicada às OTAs estudadas, permite concluir que é possível capturar uma consciência coletiva destas organizações, e que, apesar das constantes oscilações, esta consciência coletiva é determinada pela e ao mesmo tempo determinante do comportamento dos/as trabalhadores/as de cada organização de trabalho. Tal reflexão permite concluir que existem 3 tipologias de consciência dominantes nas Organizações de Trabalho Associado sob autogestão, a saber:

$\gg 1^{\mathrm{a}}$ forma de consciência - ultrageneralização e reprodução de perspectivas moralmente conservadoras das relações sociais dominantes - alienação subjetiva;

$\Perp 2^{\mathrm{a}}$ forma de consciência - consciência em si. Dominância de comportamento do tipo autogestionário e autonomista marcado pela resistência na produção e pela consolidação da cooperação, da autonomia, da disciplina, da liberdade e da participação na tomada de decisões das organizações;

$» 3^{\mathrm{a}}$ forma de consciência - consciência para si. Dominância da solidariedade humana e de classe. Trata-se da experimentação da livre práxis, cristalizada por práticas contestatórias ao sociometabolismo do capital: seja pelo qualificado exercício autogestionário no interior da unidade produtiva, seja pela integração da atividade econômica com outras experiências produtivas solidárias; ou ainda pela luta política ampliada, consolidada pela integração sociopolítica e cultural com movimentos populares e com a comunidade na qual a OTA está inserida.

A partir desta tipologia, constata-se que dentre as OTAS pesquisadas, a OTA 4 tem predominância da tipologia da primeira forma de consciência; a OTA 3 apresenta níveis intermediários, ajustando-se à segunda forma de consciências; as OTAs 1 e 2 apresentam dominância da terceira forma de consciência. Abaixo seguem alguns instrumentos metodológicos desenvolvidos para a tabulação dos dados da pesquisa, acompanhados de algumas observações interpretativas (Imagens 1, 2 e 3). 
Imagem 1 - autogestômetro institucional/organizacional da OTA $3^{15}$ :

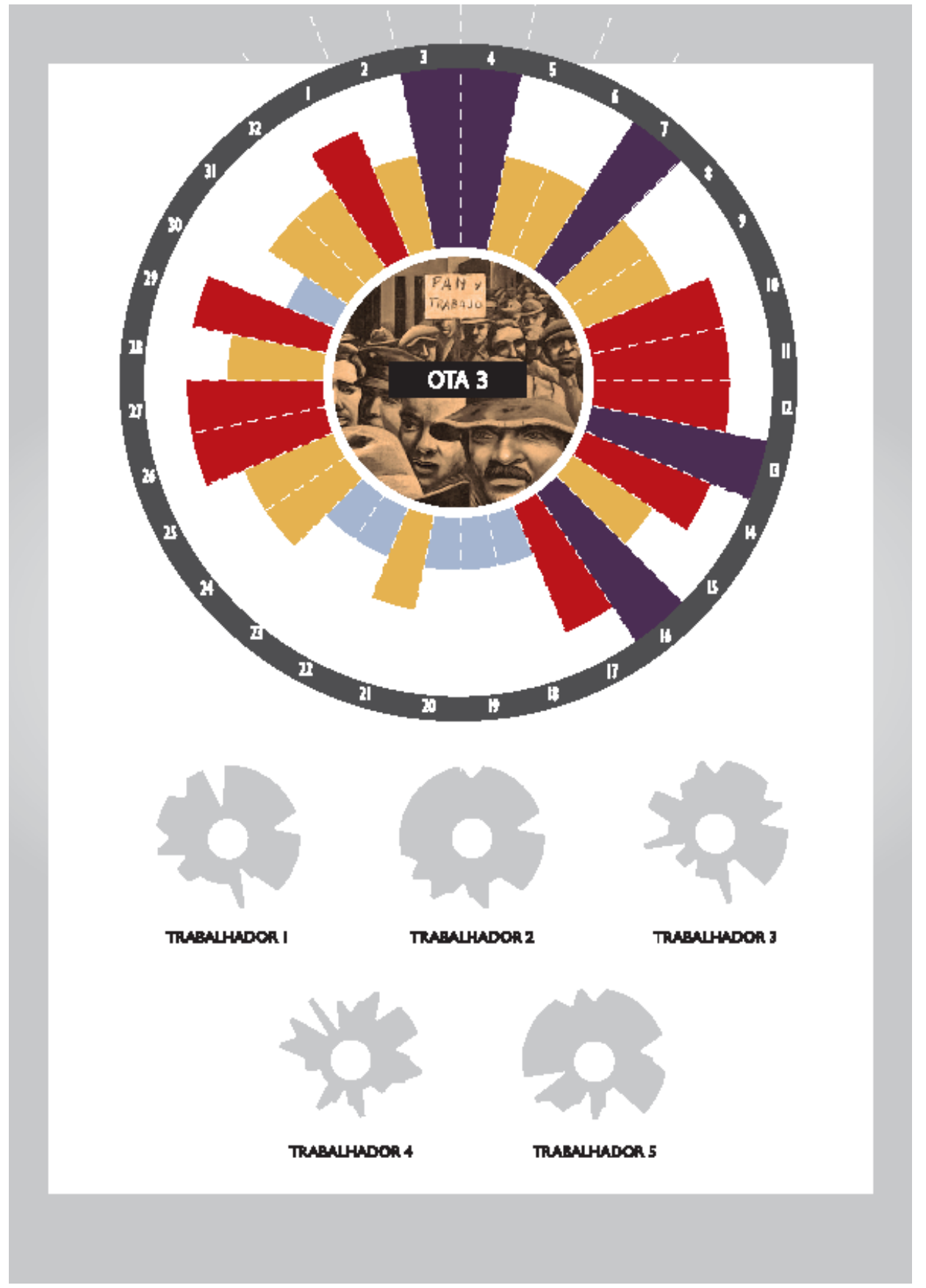

$15 \mathrm{O}$ autogestômetro institucional (Imagem 1, parte colorida) foi elaborado com o objetivo de organizar graficamente os elementos da pesquisa de campo a partir da definição de 32 indicadores institucionais divididos em três grandes blocos estruturantes. Para cada indicador foram fixados quatro níveis para quantificar maiores e menores tendências institucionais com mediações propícias para o desenvolvimento da consciência e prática autogestionária representadas por barras coloridas, definidas a partir do centro em direção às extremidades do círculo da seguinte forma: (1) socialmente inaceitável (cor lavanda); (2) aceitável (cor amarela); (3) socialmente necessário (cor vermelha); (4) padrão idealizado (cor roxa). Os indicadores e níveis foram classificados com base num quadro de tabulação, formulado a partir das informações obtidas pela aplicação do roteiro semiestruturado para entrevistas dos informantes-chave e coleta de dados referentes às OTAs. Na parte baixa da imagem 3 seguem 5 imagens dos aspectos comportamentais dos trabalhadores da OTA 3, para fins comparativos.

Barbarói, Santa Cruz do Sul, n.53, p.<227-250>, jan./jun. 2019 
Imagem 2 - autogestômetros institucionais das 4 OTAs investigadas, em perspectiva comparada por contraste de cor - OTA 1 , OTA 2, OTA 3 e OTA $4 .{ }^{16}$
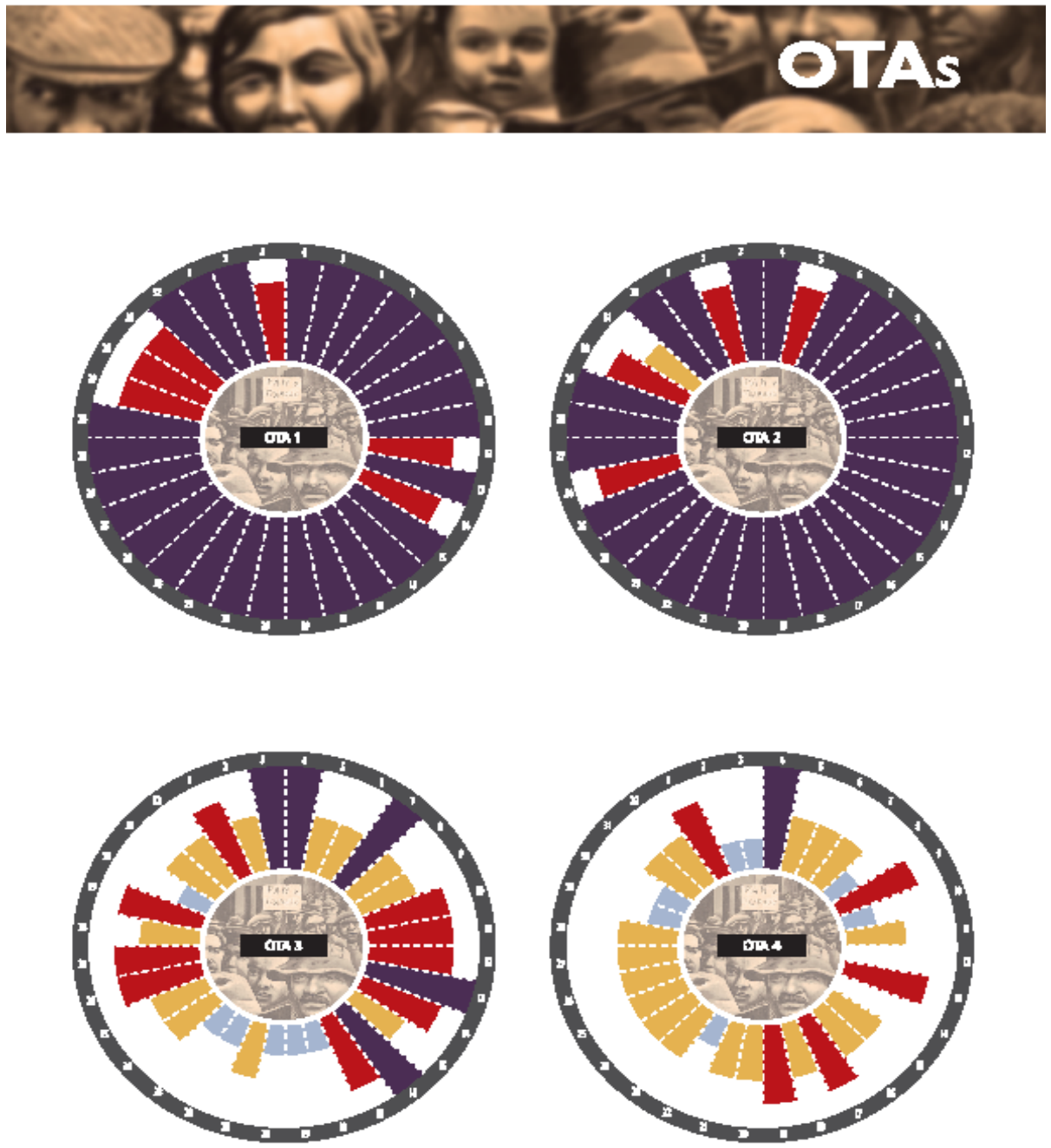

${ }^{16}$ Nas OTAs 1 e 2 predomina a cor roxa sendo que a rosácea é visivelmente mais ampla que nas OTAs 3 e 4 . Constatou-se que as OTAs 1 e 2 apresentam dominância da terceira forma de consciência.

Barbarói, Santa Cruz do Sul, n.53, p.<227-250>, jan./jun. 2019 
Imagem 3 - Quadro comparativo por contraste dos indicadores de consciência dos trabalhadores nas 4 OTAs ${ }^{17}$
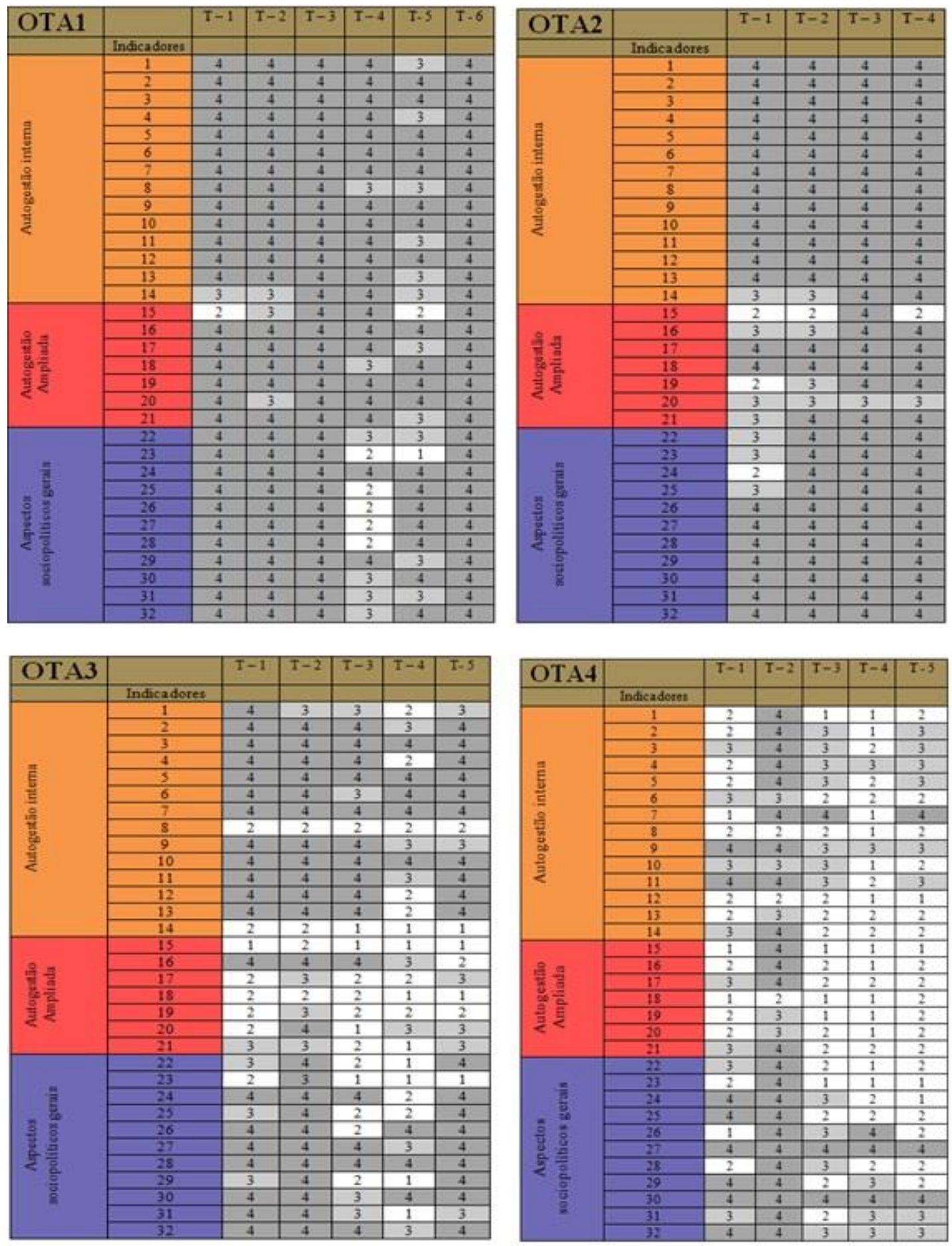

17 A diferença entre os distintos níveis de consciência dos trabalhadores está representada pelo contraste nos 4 quadros da figura 3, onde cada quadro se refere a uma organização de Trabalho Associado (OTA 1, OTA 2, OTA 3 e OTA 4). Os 32 indicadores estão dispostos em linha. As cores cinza escuro, cinza claro e branco significam: (4) cinza escuro - nível alto de consciência; (3) cinza claro - nível moderado de consciência; (2) e (1) cor branca - níveis fraco e muito fraco de consciência. Os trabalhadores 1, 2, 3 correspondem a T-1, T-2, T-3 etc. Note-se que quanto mais escuro for o quadro, mais elevado o nível de consciência de cada trabalhador e mais elevado o nível de consciência predominante na OTA. O exame por contraste evidencia uma importante diferença entre os níveis de consciência dos trabalhadores das OTAs 1 e 2 se comparados com os níveis de consciência dos trabalhadores das OTAs 3 e 4.

Barbarói, Santa Cruz do Sul, n.53, p.<227-250>,jan./jun. 2019 
O cruzamento das imagens 2 e 3 permite concluir que alguns componentes autogestionários/institucionais das OTAs impulsionam um posicionamento politicamente engajado, favorecendo o despertar de uma nova consciência nos trabalhadores (consciência para si ou de classe - $3^{\text {a }}$ forma de consciência). Algumas OTAs sustentam suas experiências em bases favoráveis a outra forma de perceber o mundo e de interagir neste. Os indicadores comportamentais evidenciam que a solidariedade de classe está presente no imaginário dos trabalhadores das OTAs 1 e 2, inclusive numa perspectiva internacionalista. A consciência e a solidariedade dos trabalhadores se confirmam na prática concreta destas, que apresentam perspectivas de confluência dos seus objetivos corporativos com bandeiras de lutas políticas mais amplas e com a socialização dos avanços obtidos no interior da sua organização, especialmente pela integração sociopolítica das unidades produtivas à comunidade nas quais estão inseridas. É a livre práxis estabelecida na autogestão ampliada: da resistência e reivindicação na produção à contestação social do capital.

Numa segunda tipologia de OTAs, a cooperação, a autonomia, a disciplina, a liberdade e a participação também se encontram em níveis avançados ( $2^{\mathrm{a}}$ forma de consciência consciência em si). OTAs deste tipo são organizações consolidadas que já superaram momentos muito difíceis e apresentam uma aguçada sintonia coletiva. No entanto, a estabilidade no processo de trabalho e a boa situação financeira podem levar OTAs que se encaixam nesta tipologia a uma condição de estagnação: esta situação pode ser perigosa e precisa ser contornada. Algumas vezes os canais de comunicação e participação perdem funcionalidade porque tudo vai bem e não há mais o que discutir. São OTAs que apresentam um histórico de intenso engajamento político com práticas formativas diversas, mas com o passar dos anos passaram a priorizar tarefas de gestão do empreendimento e demandas econômico-corporativos, desatentando para as práticas formativas dos seus trabalhadores e o seu relacionamento com a comunidade local. Para Sartre, é a livre práxis do grupo organizado cristalizada em práxis constituída: quando o grupo se endurece e o que era movimento se torna rotina, o que era ação converte-se em procedimentos (1979). As OTAs com este perfil tendem a estimular um comportamento do tipo autogestionário/autonomista, como equivalente, na tipologia de Iasi (2012), à segunda forma de consciência. Este é o caso da OTA número 3; a resistência na produção é o traço marcante deste tipo de organização.

Os resultados relacionados aos aspectos sociopolíticos da pesquisa (obtidos a partir das 83 perguntas dirigidas aos trabalhadores/as) demonstraram que alguns trabalhadores ainda têm um conhecimento muito superficial de assuntos, por assim dizer, relevantes ao cotidiano Barbarói, Santa Cruz do Sul, n.53, p.<227-250>, jan./jun. 2019 
da classe trabalhadora. Esses resultados são um tanto alarmantes e podem evidenciar uma terceira tipologia de OTA, com predominância de trabalhadores com comportamentos típicos da primeira forma de consciência, como a ultrageneralização e a reprodução de perspectivas moralmente conservadoras. O fragilizado entendimento dos aspectos políticos e sociais mais relevantes, somado à falta de compreensão mínima sobre o que venha a ser a autogestão, mesmo no sentido de autonomia ou de autodeterminação, revela a fragilidade dos componentes institucionais destes empreendimentos e põe em dúvida as perspectivas emancipatórias destes. Mesmo existindo diferentes maneiras de cooperar, participar e protagonizar no interior das OTAs; são duvidosas as potencialidades emancipatórias das OTAs com este perfil. O fortalecimento da sua organicidade é tarefa urgente e necessária. Alguns trabalhadores de organizações com este perfil apresentaram dificuldades em compreender que o seu trabalho está inserido num contexto mais amplo do sociometabolismo do capital ou de forma mais simplificada, que os acontecimentos no interior da OTA também são influenciados pelo movimento de outros atores importantes como o Estado e os agentes privados do Mercado.

O distanciamento ocorrido nas últimas décadas entre os movimentos populares e o campo do Trabalho Associado no Brasil, ocasionou um afastamento das OTAs do campo do enfrentamento político. Neste sentido, a pesquisa revelou que a relação entre as OTAs pesquisadas e os movimentos-referência ocorre de várias maneiras: desde uma forma mais orgânica e integrada (relacionada à terceira forma de consciência), ou como uma mera referência genérica - quando os movimentos populares são mencionados no sentido de representarem um horizonte abstrato ou uma bandeira de luta idealizada, comportamento típico da primeira e segunda forma de consciência.

Quando os entrevistados foram consultados sobre o seu percurso militante, constatouse que em cada OTA havia no mínimo um/a trabalhador/a com percurso militante resultante de experiências anteriores ao trabalho no empreendimento e que ingressaram neste em razão da militância política. No entanto, um interessante elemento diferencia as OTAs $n^{\circ} 1$ e $n^{\circ} 2$ das OTAs 3 e 4. Nas OTAS 1 e 2 constatou-se a existência de percurso militante em mais de um trabalhador, e que se efetivou após o ingresso deste na OTA. Ou seja: é possível que as mediações políticas nestas OTAs tenham sido capazes de despertar a consciência dos seus trabalhadores e provocar a superação da primeira e por que não dizer, da segunda forma de consciência; inserindo-os organicamente em alguma luta mais ampla, para além da atividade na unidade produtiva do empreendimento. O mesmo não ocorreu nas OTAs 3 e 4 (com dominância da primeira e segunda forma de consciência), nas quais os únicos militantes Barbarói, Santa Cruz do Sul, n.53, p.<227-250>,jan./jun. 2019 
existentes nas organizações tinham percurso militante constituído anteriormente ao ingresso na OTA e declararam estar afastados das atividades nos movimentos há um bom tempo.

Conclui-se que os indicadores institucionais "participação institucional da OTA em movimentos populares ou organizações sociais" e "participação destes na OTA" combinado com qualificados índices de "repartição do poder" tornam-se variáveis determinantes num duplo sentido: (1) como mediação necessária para o surgimento de embriões da nova consciência dos trabalhadores; (2) como vetor indispensável para a superação dos objetivos econômico-corporativos das OTAs.

As evidências do campo sugerem que a incorporação das OTAs às lutas políticas mais amplas (reivindicação e contestação) a partir da relação orgânica com movimentos e organizações populares torna-se um indispensável caminho para a possibilidade de superação dos objetivos unicamente corporativos das OTAs; elevando-as à condição de sujeito político capaz de incidir na correlação de forças com eventuais possibilidades de disputa pela implantação de seu projeto político.

\title{
ADVANCES AND CHALLENGES OF ASSOCIATED WORK IN SELF- MANAGEMENT PROCESS
}

\begin{abstract}
The aim of this research is to verify if and to what extent the self-management process in four Associated Work Organizations drives daily transformations of labor relations and is related to other broader perspectives of political struggle. Such an approach, influenced by action research and worker poll, interprets the impact of the relationship (self-management $\mathrm{x}$ consciousness) and its constraints, to problematize the limits and possibilities of selfmanagement as mediation to improve the process of self-determination and self-determination workers, that is: the ruptures and continuities of Work Associated with the old form deserve and need to be unveiled. The intersection and interpretation of the institutional and behavioral indicators used in the research conclude the existence of 3 dominant typologies of consciousness in Associate Work Organizations in self-management process.
\end{abstract}

Key-words: Process of Consciousness; Self-management; Associate Work Organizations.

\section{AVANCES Y DESAFÍOS DEL TRABAJO ASOCIADO EN EL PROCESO DE AUTO- GESTIÓN}

\section{Resumen}

El patrón de sociabilidad forjado por el capital no puede ser superado por decreto, como en un pase de hechizos, o por la simple socialización de los medios de producción. El objetivo de esta investigación es verificar si, y en qué medida, el proceso autogestionario en cuatro Organizaciones de Trabajo Asociado impulsa transformaciones cotidianas de las relaciones de trabajo, y se relaciona con otras perspectivas más amplias de lucha política. Este enfoque, influenciado por la investigación-acción y la encuesta obrera, interpreta el impacto de la relación (autogestión x conciencia) y sus condicionantes, para problematizar los límites y las 
posibilidades de la autogestión como mediación para perfeccionar el proceso de conciencia y autodeterminación de los / as, los trabajadores / as, es decir: las rupturas y las continuidades del Trabajo Asociado con la antigua forma merecen y necesitan ser desveladas. La intersección e interpretación de los indicadores institucionales y de comportamiento utilizados en la investigación concluyen la existencia de 3 tipologías dominantes de conciencia en las Organizaciones de Trabajo Asociadas en el proceso de autogestión.

Palabras-clave: Proceso de Conciencia; autogestión; Organizaciones de Trabajo Asociado.

\section{REFERÊNCIAS}

COLETIVO DE COMUNICAÇÃO, CULTURA E JUVENTUDE DA VIA CAMPESINA.

Agitação e propaganda no processo de transformação social. São Paulo: Via Campesina, 2007.

ELIAS, N. A sociedade dos indivíduos. Rio de Janeiro: Zahar, 1994.

DAL RI, N. M.; VIEITEZ, C. G. Trabalho associado e mudança social. In: DAL RI, N. M. [org.]. Trabalho Associado, Economia Solidária e Mudança Social na América Latina. São Paulo: Cultura Acadêmica; Marília: Oficina Universitária; Montevidéu: Editorial Procoas, 2010.

DAL RI, N. M.; VIEITEZ, C., G. Movimentos Sociais, Trabalho Associado e Educação: Reformas e Rupturas. In: NOVAES, Henrique Tahan; BATISTA, Eraldo Leme. (orgs.) Trabalho, Educação e Reprodução Social - As contradições do capital no século XXI. Bauru, SP: Canal 6, 2011.

DAL RI, N. M.; VIEITEZ, Candido Giraldez. Trabalho associado. Rio de Janeiro: Dp\&A, 2001.

FREUD, S. Esboço de psicanálise. In: Os pensadores. São Paulo: Abril cultural, 1978.

GAIGER, L. I. O mapeamento nacional e o conhecimento da Economia Solidária. Revista da Associação Brasileira de Estudos do Trabalho, v.12, n.1. 2014, p. 7-24.

GARCIA, S. Teatro da militância. São Paulo: Perspectiva/Edusp,1990.

GUILLERM, A.; BOURDET, Y. Autogestão: uma mudança radical. Rio de Janeiro: Zahar, 1976.

IASI, M. L. As metamorfoses da Consciência de Classe: o PT entre a negação e o consentimento. São Paulo: Expressão Popular, 2012.

IASI, M. L. Ensaios sobre consciência e emancipação. São Paulo: Expressão Popular, 2007.

IASI, M. L. Processo de Consciência. São Paulo: CPV, 1999.

MARX, K. A enquete operária - o questionário de 1880. Anexo 1. In: THIOLLENT, Michel. Crítica metodológica, investigação social e enquete operária. São Paulo: Pólis, 1981.

MARX, K. Instruções para os Delegados do Conselho Geral Provisório: as diferentes questões. In: BARATA-MOURA, J.; CHITAS, E.; MELO, F.; PINA, A. (Orgs.). Marx e Engels: Obras 
Escolhidas em Três Tomos. Lisboa: Edições Avante, 1982. Disponível em:

<http://www.marxists.org/portugues/marx/1866/08/instrucoes.htm>. Acesso em: 29 jan. 2019.

MARX, K. O capital. Livro 1. Rio de Janeiro: Civilização Brasileira, 1998. Livro 1.

MÉSZÁROS, I. Para além do capital. Campinas: Editora da Unicamp/Boitempo, 2011.

MOTHÉ, D. L"Autogestion goutte a goutte. Éditions Du Centurion. Paris, 1980 apud NASCIMENTO, Cláudio. Socialismo Autogestionário. Disponível em <www.contag.org.br/imagens/f763socialismoClaudioNascimento.pdf> Acesso em: 25 mar. 2019.

NASCIMENTO, C. Do "beco dos sapos" aos canaviais de Catende. Brasília: SENAES, 2004.

NASCIMENTO, C. Momentos e ideias decisivos para uma história da autogestão. s/d. s/e. Disponível em: <http://claudioautogestao.com.br/wp-content/uploads/2014/04/Elementospara-uma-historia-daautogest\%C3\%A3o.pdf >. Acesso em: 10 jan. 2019

NOVAES, H. T. (Org.). O retorno do caracol à sua concha: alienação e desalienação em associações de trabalhadores. São Paulo: Expressão Popular, 2011.

NUNES, T. de G. Autogestão em perspectiva comparada - quatro organizações de trabalho associado na resistência da produção à contestação do capital. Niterói. 239 p. Doutorado em Ciências Jurídicas e Sociais. Programa de Pós-Graduação em Sociologia e Direito, Universidade Federal Fluminense, Brasil. 2016. Recuperado de https://sucupira.capes.gov.br/sucupira/public/consultas/coleta/trabalhoConclusao/viewTrabalh oConclusao.jsf?popup=true\&id_trabalho $=4955605$

SARTRE, J.P. Crítica de la Razón Dialéctica. Buenos Aires: Editorial Losada, v.1, 1979.

THIOLLENT, M. Crítica metodológica, investigação social e enquete operária. São Paulo: Pólis, 1981.

TIRIBA, L. Economia popular e cultura do trabalho - pedagogia da produção associada. Ijuí: Unijuí Editora, 2001.

Data de recebimento: 18/01/2019

Data de aceite: 19/19/2019

\section{Sobre o autor:}

Tiago de Garcia Nunes é Docente no Programa de Pós-graduação em Política Social e Direitos Humanos da Universidade Católica de Pelotas/ Brasil. Doutor em Ciências Sociais e Jurídicas pelo Programa de Pós-Graduação em Sociologia e Direito da Universidade Federal Fluminense. Endereço Eletrônico: tiago.nunes@ucpel.edu.br 